\title{
Toy department within the toy department? Online sports journalists and professional legitimacy
}

\begin{abstract}
This study explores the professional legitimacy of online sports journalists as an emergent group within the occupation in the U.K. Two typologies of sports journalists working for national news organisations are identified (traditional and online) and semistructured interviews conducted with both groups. Drawing on concepts from the sociology of professions, the study applies three sub-definitions of professionalism normative, cognitive and evaluative - to online sports journalists. The findings indicate that online sports journalists both see themselves and are seen as professionally illegitimate in all three sub-definitions despite a reputation for digital innovation. Sports journalists consider their professional jurisdiction to be defined by traditional norms, values and practices while refusing to accommodate newer, digitally native approaches. Secondly, traditional sports journalists enhance their legitimacy by positioning online colleagues as a 'toy department within a toy department', similar to how news journalists disparage the sports desk to elevate their own professional claims.
\end{abstract}

\section{Keywords}

Sports journalism, online journalism, professionalism, digital journalism, boundary work.

\section{Introduction}

Historically, journalists have resisted standard conventions of professionalisation and preferred to situate themselves as social outsiders. However, journalism's transformation into a graduate career is leading to a pursuit of professional respectability (Aldridge and Evetts, 2003). Further, 'professionalism' has become an important discourse to journalists as a means of maintaining their dominant role in response to losing monopoly control over information in the digital age (Carlson and Lewis, 2015; Lewis, 2012; Waisbord, 2013). Journalists have seen their norms and practices adopted by nonprofessionals such as bloggers and citizen journalists, which have led to searching questions for journalism's jurisdictional control (Anderson 2008; Anderson and Schudson 2008). The emergence of online journalists within newsrooms and the advent of digitally native practices have further challenged attempts to define clear professional boundaries (Carlson, 2015; Hartley, 2013; Singer, 2003; Singer et al, 1999).

These findings do not automatically apply to sports journalists. News journalists distance their professional claims from those of sports journalists by using the disparaging 'toy department' label (Oates and Pauly, 2004; Rowe 2004, 2007; Salwen and Garrison 1998). Sports journalism is therefore isolated within the newsroom and must pursue a professional project of its own. The 'toy department' reputation is a source of insecurity for sports journalists, who strive for greater professional recognition (Salwen and Garrison, 1998). Little is known about online sports journalists, particularly in the U.K. context, and what they have meant for professionalism. This study aims to address this 
relatively neglected area of the newsroom to provide both a more comprehensive and nuanced understanding of journalism professionalism.

\section{Sports journalism and professionalism}

The sociology of professions has become a common theoretical framework in exploring changes to journalism in the digital age (Anderson, 2008; Anderson and Schudson, 2008; Carlson and Lewis, 2015; Lewis, 2012; Meltzer and Martick, 2017; Singer, 2003). Journalism professionalism studies in recent years have reflected the neo-Weberian turn in the 1970s and 1980s towards exploring reasons why occupations strive for professional recognition rather than whether they warrant such status (Aldridge and Evetts, 2003; Anderson, 2008; Anderson and Schudson, 2008; Lewis, 2012; Singer, 2003). Professional claims to special knowledge and skills are made to enhance prestige and status, which can then be converted into social and economic rewards (Larson, 1977). Abbott (1988) goes further by linking these knowledge claims to daily practices which, combined, allow the occupational group to ask society to recognise exclusive rights over performing a particular function in society, known as a 'jurisdiction'. Journalists laid claim to a jurisdiction largely through the norm of objectivity that gave them the power to define, gather and disseminate news and separate them from other professional fields such as public relations (Abbott, 1988; Schudson 2001). The process of establishing a jurisdiction also involves marking professional boundaries, which has become increasingly challenging for journalists in the digital age (Lewis, 2012). Journalism's boundary work is discursively constructed because it lacks the structural features of other professions, such as credentials and licences to practise. Therefore, journalists engage in rhetoric and narrative around their expertise to legitimate their cultural authority within society (Lewis, 2012; Zelizer, 1992). Boundary work has become an important concept in journalism research for understanding 'distinctions such as professional/amateur, producer/user and journalist/non-journalist’ (Lewis, 2012: 842).

There are clear dimensions to the sociological construct of journalism professionalism. The concept of objectivity is set within a broader normative framework that also accommodates ethics and public service (Deuze, 2004; Singer, 2003). However, the normative dimension does not explain the performative aspects of journalism practice. Singer (2003), in invoking Larson's (1977) work, provides a comprehensive perspective on professionalism in journalism by also pointing to cognitive and evaluative functions. The cognitive dimension identifies the expertise - knowledge, skills and qualifications that journalists must demonstrate to secure membership to the occupational group. The evaluative dimension refers to the extent to which the occupational group is autonomous and can dictate the terms of its norms, values, routines and practices free from external influence, whether they be managerial, commercial, or governmental.

As Carlson (2015: 2) notes, boundary work is essentially a jurisdictional struggle over 'who counts as a journalist, what counts as journalism, what is appropriate journalistic behaviour and what is deviant'. In the case of sports journalism, deviancy is a particular concern. Sports journalism's 'toy department' reputation can be analytically linked to the three sub-definitions of professionalism (Larson 1977; Singer 2003). News journalists 
accuse sports journalists of having tenuous professional claims through the 'toy department' label, which is a manifestation of perceived normative, cognitive and evaluative failure. Sports journalists therefore assert rather weak claims to professionalism despite their high economic importance to news organisations in attracting audiences and advertisers (Boyle, 2006; Rowe, 2004). Sports journalists have struggled to establish a clear jurisdiction because there is scepticism around their claims to special knowledge and skills. Consequently, sports journalists' ability to establish exclusive rights is limited, exposing them to accusations that they are merely 'fans with typewriters’ (Boyle, 2006). Sports journalism’s professional struggle in securing jurisdictional control involves convincing the wider newsroom and the public that its knowledge and practices are distinct from both professional fields (public relations) and non-professional fields (blogging). On the surface, sports journalists appear to undermine the professional claims of news colleagues. However, Oates and Pauly (2007) have argued news journalists use the 'toy department' label as an ethical straw to enhance their own legitimacy. By disparaging the conduct and behaviour of the sports desk, the news desk cements its own professional claims.

The 'toy department' label operates on the following normative assumptions. Sports journalists identify more closely with subjectivity than objectivity in prioritising opinion over news. Sports journalists are also primarily concerned with rumour and speculation rather than hard facts. Sports journalists also fail to be neutral and unbiased in their reportage (Boyle, 2006). Further, 'sport' is considered trivial subject matter when compared to weightier 'life and death' news concerns. Sports journalism is also accused of failing to deliver at a cognitive level. News journalists intervene when serious and complex off-field matters need covering because sports journalists lack the technical journalistic competencies (Boyle, 2006; Sugden and Tomlinson, 2007). Sports journalists' professional problems are exacerbated beyond the newsroom by increasing public expectations to investigate the social consequences, such as doping, corruption, and gambling, of a highly commercialised sports environment (Boyle, 2006; Rowe, 2017). Evaluatively, sports journalists are perceived as lacking autonomy in being controlled by sources and lacking professional distance (Sugden and Tomlinson, 2007). The 'toy department' reputation is considered to contribute to a lack of career mobility within the newsroom with a lack of sports journalists graduating to senior positions in newsrooms (Rowe, 2004).

Sports journalists generally rile against and reject the 'toy department' label. Garrison (1989:3-23) asserts that sports journalism has 'become as sophisticated as the city desk and has turned the corner into legitimate journalism'. Garrison (1989) argues that sports journalists have become more objective in reporting both the positive and negative stories around sports teams while committing to a wider range of stories that accommodate offfield issues, such as politics and business, as well as on-field events. However, sports journalists are troubled by their 'toy department' reputation. Salwen and Garrison (1998) have noted sports journalists' poor reputation is their biggest professional concern above job security and the future of journalism. Therefore, sports journalism's pursuit of respectability and status is an important aspect of its professional project. Since Salwen and Garrison’s study, sports journalists in the digital age must convince the public of 
their occupational distinctiveness from outsiders, such as fans, bloggers, clubs and organisations (Hutchins and Rowe, 2012; McEnnis, 2017). Here, the 'toy department' has become a malleable concept that can attempt to be shed and transferred. Whiteside et al (2012) have pondered whether bloggers were a 'new' toy department as they lacked critical analysis and contextualisation of subject matter when compared to 'professional' sports journalists.

Journalists situate their boundary work within rituals and routines that also act as a means of occupational socialization in passing on the established ways things should be done (Schudson, 2001; Singer, 2004). Sports journalists rely on their accreditation and access to professional sports to assert exclusive rights and mark occupational boundaries. For instance, sports journalists ritually attempt to demonstrate objectivity and impartiality at sports events by instilling an informal code of 'no cheering' in press boxes (Steen, 2014). Sports reporters are mobilised according to highly routinised practice that involves covering specialist beats organised according to different sports or, in the case of soccer, geographical lines. They involve attending sports events, press conferences and media briefings. Sports journalism is defined by its access to the professional sports environment. Boyle and Haynes (2009) refer to U.K. sports journalists being dispatched on lengthy ship journeys to Australia to cover cricket tours in the early 1900s.

Sports journalists consider professional knowledge to be situated in both experience of covering sports events and access to inside information within professional sports. Interviewing and developing close source relations are therefore seen as highly valued skills. Sports journalists also play on their beat reporting experiences (McEnnis, 2018). Aldridge and Evetts (2003: 560) note 'journalists have an unusually elaborate and frequently paraded occupational belief system in which rugged individualism, frightening but charismatic editors and outrageous behavior are central themes'. Similarly, sports journalists build their mythology around a 'press pack', defined as elite reporters in traditional roles who work for rival news organisations but operate as wider colleagues through a blend of competition and camaraderie (Sugden and Tomlinson, 2007). This mythology is enhanced by broader cultural production, such as autobiographies, that tell anecdotes of close source relationships with sportspeople (McEnnis, 2018). Further, the broadcast media confer prestige and status on to print sports journalists by including them as talking heads on television shows (Boyle, 2006).

\section{The emergence of online sports journalists}

Previous research into the news desk has found online journalists are unsuccessfully integrated into the occupational group. News organisations initially adopted a cautious approach to online publishing in the late 1990s for fear of compromising print revenues. (Bradshaw and Rohumaa, 2011). They devoted meagre resources to their web operation and the early online journalists' duties involved copying and pasting newspaper content on to the website (Singer et al, 1999). News organisations were effectively creating a two-tier newsroom with different routines, rituals and relationships. The volume of content being published by news organisations online is leading to concerns that quantity 
is at the expense of quality (Karlsson, 2011; Starkman, 2010). The pressure to produce more content in less time has led to the lifting of rivals' stories, a process which Curran (2011: 116) has described as 'creative cannibalisation'.

These different routines and practices have led to an 'artificial "us" and "them" culture' between print journalists and their dotcom colleagues' (Bradshaw and Rohumaa, 2011: 9). Print journalists and their online colleagues rarely interact within the newsroom on a professional basis (Fahmy, 2008). Online journalists associate good journalism with newspapers and lack the resources and autonomy to produce 'proper' news themselves (Hartley, 2013). Singer (2003) applied normative, cognitive and evaluative dimensions to online journalists. Normatively, online journalists are driven by speed often at the expense of verification and fact-checking. The cognitive function involves repurposing and repackaging second-hand content along with basic HTML web programming skills. Evaluatively, online journalists lack autonomy from commercial forces as news organisations' attempts to make money online take them into areas such as sponsored content, which can lead to editorial interference. Further, online journalists struggle to obtain the prestige that those in traditional roles enjoy, such as securing press accreditation passes to news events.

However, these findings do not necessarily apply to sports journalists. Morrison (2014) argues that the 'toy department' reputation has given sports journalism autonomy from the wider newsroom to explore digital innovation. The sports desk has used online platforms to experiment with story presentation while the 'fans with typewriters' status has helped engagement with audiences and the building of virtual communities. Further, sports journalism's fixation with statistics and data lends itself to digital storytelling. Morrison (2014:16) quotes former Washington Post sports editor and executive editor Jim Brady as wryly stating, 'It's probably the only time being considered the toy department was a good thing'. Sports journalism's significant contribution to the digital newsroom has been live blogging, which has transformed the way that 'breaking news' stories are packaged (McEnnis, 2016; Morrison, 2014; Thurman and Walters, 2013). The Guardian in the U.K. is credited with the first live blog at the 1998 World Cup in France (Smyth and Murray, 2014).

Live blogging was not the only innovation from The Guardian's online sports journalists. They also started the popular Football Weekly podcast, which involves sports journalists discussing topical events and has spawned many imitators. Freedman (2010) has noted that The Guardian site is well resourced in comparison to other web projects due to an ownership model that is conducive to longer-term investment strategies (the BBC is publicly funded through a licence fee while The Guardian is accountable to trustees rather than shareholders). Guardian.co.uk quickly began to recognise the website as a separate media product to the newspaper that required original content and its own identity. The Guardian's approach is not widespread among U.K. newspaper sports desks. English (2011) has discovered differing attitudes towards the relationship between print and online within sports desks on U.K. national newspapers. Broadsheet, quality publications such as the Daily Telegraph and The Guardian recognise the importance of web-first publishing and prioritise online over print while The Sun, a popular tabloid, 
considers newspapers to be its primary vehicle for sports news and information with digital platforms providing a supplementary service.

A further example of online sports journalism innovation is the Pulitzer Prize-winning article Snow Fall: The Avalanche at Tunnel Creek by the New York Times. Snow Fall, which told the story of leading U.S. skiers caught in an avalanche, is considered within the industry to be a landmark in experimental story presentation in the way that longform journalism can be imagined on digital platforms. Snow Fall was also notable for the way that sports editors were 'more open to experimentation and bringing the graphics and design teams in earlier in the story's process' (Morrison, 2014: 17). The phrase 'Can we snowfall this?' has become part of newsroom vernacular and is used whenever a potential opportunity arises to treat a story in highly visualised and stylised ways (Dowling and Vogan, 2015).

These innovations do not mean that the sports desk is insulated from criticisms that the web has seen a decline in journalistic standards. Hutchins and Rowe (2012: 142) found online sports journalists are 'characterised as engaging in the activity of attention grabbing rather than simply providing sports news’. Lange et al (2007) interviewed Australian Internet sports journalists and discovered they considered themselves inferior to colleagues in traditional roles, mainly because of the newness of the medium. There is also scepticism as to whether live blogging has been 'good' for journalism in that it prioritises speed at the expense of accuracy and verification (Greenslade, 2012). These contrasting claims of innovation and inadequacy suggest what online sports journalists mean for the professional project is unclear.

Little is known about online sports journalists. Interviews with 10 live bloggers found they are interpreting professional characteristics of ethics, public service and objectivity in new ways (McEnnis, 2016). Public service translates into community building through constant interaction with fans. Live bloggers demonstrate objectivity through mediating discussion among the audience. Readers contributed to ethical standards by acting as a check and balance on errors and inaccuracies. Live bloggers consider themselves autonomous and free to experiment and develop the format due to a lack of managerial interference. However, whether these re-interpretations of professional principles are widely valued and accepted across the occupational groups are unknown.

\section{Methods}

This study explores the professional legitimacy of online sports journalists. Semistructured interviews are a common methodological approach in examining journalism professionalism. This method also allows an occupational group a rarefied opportunity to reflect as the intensive nature of news work affords little opportunity for self-reflexivity and self-understanding. In-depth, semi-structured interviewing is also a common method in previous studies into sports journalism (Boyle, 2006; Hutchins and Rowe, 2012; Hutchins and Boyle, 2017; Lange et al, 2007; McEnnis, 2013, 2016, 2017; Rowe, 2004) as well as other specialist journalism rounds, such as science journalism (Fahy and Nisbet, 2011). 
The research design identifies two typologies of journalist, traditional and online, that have emerged from previous studies of modern newsrooms (Agarwal and Barthel, 2015; Deuze and Yeshua, 2001; Kronstad and Eide, 2015; Singer, 2003; Singer et al, 1999). These typologies also reflect the organisation of sports desks within U.K. national newsrooms where there is a clear division of labour between digitally native journalists who work directly with online platforms and journalists who perform field or production work that is situated in legacy newspaper practices but which may be published or republished on websites. For example, McEnnis's (2016) study of live blogging in U.K. sports desks found it to be a practice that tended to apply to desk-bound online sports journalists and did not involve journalists in classic 'newspaper-oriented' roles. Previous sports journalism research also recognises these role distinctions and division of labour both inside and outside the U.K., such as in Australia (Hutchins and Boyle, 2017; Hutchins and Rowe, 2012; Lange et al, 2007).

Specifically, a 'traditional role' is defined as newspaper-oriented work routines. Sports journalism routines have intensified, such as producing stories for both print and web, but their essential character is unchanged. A 'traditional role' includes the beat aspects of reporting, including covering press conferences and the sporting event, and more conventional source relations with professional sports insiders, such as media managers, players, and coaches (Boyle 2006; Sugden and Tomlinson, 2007). They may be leading sports writers who produce analytical/column pieces (Boyle, 2006; Rowe, 2004). Sports editors, assistant editors, and sub-editors working in newspaper production also belong to this category. 'Traditional' sports journalists may engage with digital media, such as tweeting or appearing on podcasts, but these are supplementary practices that do not define their core and primary journalistic purpose.

An 'online' journalist, however, is primarily office-based and often works directly with digital platforms, usually via content management systems. They are expected to need greater technological knowledge and be more web-savvy than their colleagues in traditional roles (Lange et al, 2007). These journalists often have the word 'online' within their job titles to signify their digitally specific role orientation. The online journalist provides a dual role of writing/producing original content and integrating, repurposing or rewriting second-hand, third party information from both inside and outside the news organisation (Hutchins and Rowe, 2012; Lange et al, 2007; McEnnis, 2016). Online-only practices include live blogging, web podcasting, repurposing newspaper content, integrating multimedia content, writing online headlines, adding hyperlinks to text, curating social media accounts and sourcing stories from websites such as Twitter (Singer et al, 1999; Hutchins and Rowe, 2012; McEnnis, 2016). The emergence of online-only sports journalism within the U.K. is starting to be recognised by the academy (English, 2011; Hutchins and Rowe, 2012; McEnnis, 2016; Steen, 2014) but little is known about the role holders themselves.

Twelve sports journalists (six in traditional roles, six in online positions) working for national, legacy print organisations were interviewed in person during a two-year period between 2014 and 2016. The sample was formulated through a combination of the 
researcher's industry network from a professional background in sports journalism and the snowballing effect of participants recommending others. The age range of the sample was 24-40 which applied to both online and traditional sports journalism contexts. The sample included one female, which reflects the lack of diversity within national newspaper sports desks (Boyle, 2006; Franks and O’Neill, 2016). Small samples are common in sports journalism research because of the occupation's status as a specialism within the newsroom (Boyle, 2006; Hutchins and Rowe, 2012; McEnnis, 2013, 2016, 2017). Six national newspaper groups were represented in the sample and are categorised into popular (tabloids such as The Sun, Daily Mirror, Daily Mail) and quality (broadsheets including The Guardian and The Times).

Interviews lasted between 45 minutes and 1 hour 30 minutes and took place in informal settings including coffee shops, bars, and staff canteens. Participants are anonymised and referred to by their occupational roles. This project is part of a wider study into sports journalists' professional identity in the digital age. The data was coded according to a priori themes (Strauss and Corbin, 1990), specifically the three dimensions of professionalism, normative, cognitive and evaluative (Larson, 1977; Singer, 2003).

\section{Results and discussion}

\section{Normative dimension: ethics, public service, spelling, verification, trust}

Journalists' professional obligations include sound ethical behaviour and judgment as well as acting in the best interests of society. Singer (2003) identifies accuracy, verification and trust as central ethical concerns. Traditional sports journalists believed they already fulfil their normative obligations even though the occupation is criticised for a lack of critical inquiry. However, online sports journalists recognised they are not fulfilling normative expectations of holding power to account. One online sports journalist for a quality newspaper stated, 'I think of a journalist as someone who does something a bit more investigative....someone who breaks the story. I got my NUJ card ${ }^{1}$ through the other day and thought wow I'm an actual journalist'.

Participants in the study also raised concerns that online sports journalists' practices are ethically unsound. Traditional sports journalists criticised online journalists for sourcing stories and information from elsewhere on the web for two reasons. Firstly, they considered this second-hand reporting method to be a form of plagiarism of someone else's work. One assistant sports editor for a popular newspaper stated, 'Most stories are picked up from other sources - they haven't got contacts'. A reporter for a popular newspaper stated, 'You're just in the office, reading websites, reading newspapers, making the odd call'. Secondly, traditional sports journalists believed that online journalists were rewriting and regurgitating these stories without conducting checks on the accuracy and veracity of the information. Traditional sports journalists were critical that their work was not being published by online sports journalists in favour of uploading material from other sites. A sports reporter for a popular newspaper said, 
'They tend to be scouring global websites, every newspaper, every foreign website, every foreign newspaper and they are lifting and putting it up (on the website) straight away'. Another reporter with a popular newspaper said, “All we've got here is people shovelling stuff from one website to their own website’. Participants also voiced concerns the quality control process for digital platforms was inferior to the newspaper. As a result, online publishing is characterised by inaccuracies such as incorrect facts and misspellings. An assistant sports editor for a popular newspaper said, 'There doesn't seem to be any subbing online - not like in the paper'.

Online sports journalists were also criticised for producing content, such as live blogs and news stories, sourced from television feeds of sports events and press conferences. This approach can be considered to be unethical in two ways. First, it can generate a misleading impression that the story is produced by first-hand, on-the-spot reportage. Second, broadcast will convey a partial picture of the actual situation and relies on the editorial decisions of television directors. An online sports journalist for a popular newspaper agreed that there were ethical limitations to their own practice by stating,

'It's a very one-dimensional view - at a live event, you get the crowd reaction, you can look away and see what is happening on the bench. It's stuff the TV broadcast is not necessarily going to show you. You get to see the post-match conferences as well. (As an online journalist) you only get to see the interviews that you see on TV'.

However, this practice is rather compelling for news organisations in an online environment dictated by speed. An online sports journalist can immediately publish on websites and social media platforms by watching live television broadcasts rather than wait for reporters to file copy from stadiums. Further, traditional sports journalists' perspective on this matter may derive more from fears that core routines are being displaced than a genuine concern for ethics. News organisations commit substantive resources towards the travel and accommodation of globe-trotting reporters and this could be endangered by the proliferation of sports events and press conferences being broadcast live on television.

\section{Cognitive dimension: Skills, knowledge, techniques, training}

Traditional sports journalists considered the ability to cultivate contacts and sources as an important professional skill. Interviewing is also highly prized and reflects the 'beat' reporting nature of sports journalism, where attendance at press conferences and media briefings are standard routines. One online sports journalist with a quality newspaper situated professional knowledge claims in sports history, stating:

'When you write about sport you're drawing on all the sport you've ever seen. Yesterday I was doing the Burnley v Everton game and put up a goal that (Everton player) Kevin Sheedy scored in front of the Kop ${ }^{2}$ in 1986/87. He smashes in a free-kick and sticks two fingers up. The ability to be able to recall and discuss things that aren't just happening in the present gives you some kind of credibility. Someone who knows about sport.' 
However, sports journalists’ professional knowledge consists of special insights from privileged access to both the professional sports environment and regular attendance at sports events (McEnnis, 2013, 2018). Online sports journalists are generally office based and therefore lack the special insights that inform professional knowledge. A reporter for a quality newspaper stated, 'If you're just watching games on TV, you're not as informed as people who are there'. A reporter with a tabloid newspaper referred to source relations when he said, 'I'd like to see more of them out in the field, doing stuff, building up relationships, going out for lunch, having a few beers, doing things at a personal level'. Online sports journalists deferred to traditional journalists to imbue their work with authority and credibility. One online sports journalist for a quality newspaper said, 'Some of the reporters will e-mail me during a match to say "this is what's going on”. That's something I really appreciate'. Another online sports journalist for a popular newspaper said, 'To have that authority, we've got out reporters at the ground. I'm backed up by my team of reporters to add some depth'. An online journalist for a quality newspaper said, 'Because it's people on the desk writing live blogs, a lot of freelancers... and not the people in the games, who are the correspondents so in terms of respect, they are a lot more senior than us. It naturally follows - they're a job with a title'. Another online sports journalist with a quality newspaper considered digital work to be reactive and supplementary to the stories produced by beat reporters ('I feel like I'm writing a commentary on things that they've written about, things that they've presented'). One online sports journalist for a quality newspaper said, 'It's great if (online journalists) can throw in their own experience of being at sporting events in a journalism capacity rather than I was there as a spectator. It would help and you'd get more respect and give the blog a lot more credibility'.

Online sports journalists offered differing perspectives over the level of journalistic skill involved in digitally native work. One online journalist with a quality newspaper said, 'There's plenty of sports writers out there who do match reports who couldn't turn their hands to live blogs because I think it takes a different ability and skill'. Another online journalist with a quality newspaper considered immediacy to be a virtue by stating, 'In some ways it's the purest form of writing, you don't have time to finesse and play and make it perfect...you just have to write it'. However, an online sports journalist with a popular newspaper said, 'There's far more people who are able to do what I do. It's still probably a higher value skill set being a print journalist’.

Traditional sports journalists expressed concern that online journalists had not acquired sufficient professional qualifications or experience prior to employment. A common entry route into journalism in the U.K. involves the acquisition of professional qualifications awarded by the National Council for the Training of Journalists (NCTJ). Historically, journalists have been expected start their careers with local/regional newspapers before progressing to national organisations. Traditional sports journalists in this study considered this industry-valued route to not apply to online journalism. Reference was made to the youth of online sports journalists when one reporter with a popular newspaper said, 'you've got a lot of young kids coming in who haven't gone through journalism training. They haven't been through the local paper route'. An online sports journalist for a quality newspaper agreed the bar for professional entry was lower 
by stating, 'I think the standards that news organisations use to employ (online) are less strict then if they were employing for a match report in the paper or a feature'. An online sports journalist with a popular newspaper added, 'Apart from writing standard English, I don't think there's that many qualifications you need in order to do it'. However, another online sports journalist with a quality newspaper argued that formal qualifications were not relevant to digital journalism by saying,

'There was a time when you needed to have a journalism degree or NCTJ to get into newspapers, maybe now qualifications don't matter as much. Maybe it's a case of if you are more of a personality then you do have a flair whether it be creating videos for YouTube or covering live blogs then maybe you don't need those qualifications in the first place.'

This study therefore found that credentials, qualifications and conventional entry routed are important discourses in establishing a professional jurisdiction around methods and practices rooted in newspaper culture. Industry qualifications are considered to be synonymous with traditional sports journalists, which helped to re-inforce their status as professionals. This narrative dis-enfranchises online sports journalists by positioning them as occupational outsiders. Online sports journalists are socialised into believing they are professionally deficient because a perceived lack of credentials mean they are undeserving of sports desk membership. Their lack of competency means that digitally native practices are by definition inferior to traditional ways of doing sports journalism.

Online sports journalists generally situated their career aspirations within traditional role orientations. However, they thought this could only be achievable if they demonstrated traditional skills outside of their standard work routines. One online sports journalist with a quality newspaper stated, 'We're not told to interview such and such but I'm arranging interviews off my own back and doing them in my own time'. Traditional sports journalists expect online journalists to aspire to conventional norms and values even though digital platforms are considered to be the future of journalism. An online sports editor with a quality newspaper pointed out, 'Digital is important for us because our digital audience is huge. Might be 10million people a day - compare that to the print circulation...I don't think anyone is thinking of a future whereby the paper picks up sales'. However, one reporter with a popular newspaper stated, 'They are young lads who probably want to be newspaper journalists’.

\section{Evaluative dimension: Autonomy, prestige, status}

Online sports journalists are commercially significant within newspaper organisations by attracting substantive web traffic but this economic usefulness did not lead to higher occupational status. A reporter for a quality newspaper indicated that the 'toy reputation' of the sports desk extended to online practices ('They value the hits but they don't want to let the "kids" into the main story'). Also, while elite newspaper sports writers can earn considerable salaries at news organisations (Boyle, 2006), leading online sports journalists do not receive similar financial recognition and reward. An online sports journalist, in discussing a highly rated colleague, indicated, 
'I'm surprised (name redacted) hasn't been headhunted - it's a digital-first culture and he's the best in the country at what he does. I know (newspaper redacted) tried to get (name redacted) once but they either offered him less or the same. He doesn't earn a huge amount. I find it weird'.

The economic value of online sports journalism could also lead to resentment elsewhere within the newsroom. An online sports journalist stated,

'Live blogs are often the most read thing on the website. If you go to the top 10 things on the (newspaper redacted) website, most days you will have minute-by-minutes ${ }^{3}$ there.

Someone said once that the proper desk got so pissed off with it, they actually rigged it so it wouldn't appear. You definitely get a snooty attitude - it's fair enough I suppose particularly if it's people who do not understand sport'.

Another online sports journalist revealed the economic success of his work did not lead to clear recognition that he was culturally valued within the newsroom, stating,

'The (newspaper redacted) has done amazingly well out of the live blogs. Something that must have brought millions of people to the site and has brought a lot of traffic. They appreciate the live blog is important. What they think of the people that do them... whether they respect them more or less. I don't know the answer to that. I don't know'.

Online sports journalists also suffered from institutional prejudices towards the Internet as a medium. One online sports journalist with a quality newspaper referred to online sports journalism's reputation for innovation in stating, 'The Guardian did good work to get live blogs in the mainstream but I think they are still viewed with suspicion and that's a digital thing. I don't think anyone from the paper would do it'. Another online journalist with a quality newspaper stated, 'I think in some ways it (live blogging) gets more respect from members of the public than it does from editors. A lot of people in charge are coming from a paper culture'. Another online sports journalist also considered reputation to be higher among audiences than colleagues by stating, 'If you are doing good minute by minutes ${ }^{2}$ and on the podcast, you will be esteemed - particularly by my generation, I'm 32'.

This study found little evidence of professional acceptance and integration. An assistant news editor on a popular newspaper referenced the toy department reputation by stating, 'Everybody who isn't online sees everyone online as below them on the sports desk, just as everyone on news sees everyone on sport as below them'. One reporter with a popular newspaper refused to acknowledge online journalists' membership of the sports desk by saying, 'I almost, rightly or wrongly, see them as another department. I would put them at the bottom of the pile'. Another reporter with a popular newspaper queried the validity of online sports journalists' professional claims by stating, 'I just don't think it's journalism'. One sports writer with a quality newspaper suggested attitudes towards online journalists varied among generations by stating, 'There was a time when 
traditional print journalism looked down on online and maybe some of the real dinosaurs still do but now it's accepted'.

Online sports journalists also considered a lack of prestige to be defined by the medium. One online sports journalist with a quality newspaper said, 'Seeing your name in print is far better than seeing your name on the web”. An online sports journalist with a popular newspaper said, 'At college, my aim was to get my name in the paper. I don't get the same from that online. I think there is a void that needs to be filled with that'. However, the same participant linked his job satisfaction to commercial factors by saying, 'Online now we can look at how many clicks and to see how many people have read what you've done, that's where my satisfaction comes from'. An online sports editor with a quality newspaper stated, 'It's always nice if a piece is used in the paper but it's nice to have an article shared a lot on facebook, tweeted, and read by lots of people'. Traditional sports journalists expressed sympathy for online journalists' lack of autonomy within a hypercommercialised digital environment. One reporter with a popular newspaper said, 'They haven't got time to pick up the phone or meet someone for lunch. They haven't got a minute from the moment they get in to the moment they leave'. Another reporter with a popular newspaper stated, 'It's not their fault a lot of the time. They're just thrown in there'.

\section{Conclusion}

The findings of this research are consistent with previous studies that have examined what online news journalists have meant for professionalism (Singer, 2003; Hartley, 2013; Agarwal and Barthel, 2015). Online sports journalists are excluded from the professional project even though sports desks are considered to be a site of digital innovation (McEnnis, 2016; Morrison, 2014; Vogan and Dowling, 2015). Little is changing in the professional acceptance and integration of online journalists despite the growing maturity of the medium and concessions within industry that digital platforms are the future of journalism. The findings here on U.K. sports journalists echo previous research in other national contexts, specifically Australia, which suggests a conservative professional culture has an international dimension (Lange et al, 2007).

Live blogging, for instance, may be an influential and widespread format but is excluded from professional discourse because the occupational group is suspicious and sceptical of new practices. Professionalism in sports journalism is still defined by normative, cognitive and evaluative interpretations historically situated in newspapers. Newer, digital role orientations and practices have not led to greater elasticity and scope in how the professional jurisdiction is defined. Instead, professional beliefs are highly resistant and entrenched with newspaper organisations where they become internalised by online sports journalists through the socialisation process. Traditional sports journalists, who patrol the boundaries of the profession, feel threatened by newer digital practices, the lack of cohesion they present to the professional project in how they undermine claims to exclusive rights, special knowledge and skills.

Normative concerns of speed over accuracy, fact-checking and verification in online work exist on the sports desk as well as the news department. Ethical issues surround the 
process of 'creative cannibalisation', the process of lifting and repurposing stories from other websites (Curran, 2011). Cognitively, online sports journalists' office-based routines are incongruous to the occupational culture where being physically present in the professional sports environment is essential to knowledge claims and narratives of expertise. Online sports journalists are also considered to lack professional credentials and qualifications, which further de-legitimises their routines and practices.

Evaluatively, online sports journalists suffer from low prestige despite their economic usefulness to news organisations. They can then find themselves positioned as professional outsiders through being described as non-members or even non-journalists. Traditional sports journalists often referred to the youth of their online colleagues to undermine their professional legitimacy, even though the age demographic of the typologies in this study was comparable.

Traditional sports journalists use their online colleagues as a 'toy department within a toy department' to conduct important boundary work in establishing their own professional legitimacy. Oates and Pauly (2007) identified the 'toy department' label as an ethical straw for news journalists to elevate the value of their news work by disparaging sports journalists. This study found that traditional sports journalists' assert their maligned professional attitudes and practices as culturally important and valuable when compared to the 'sub-standard' digitally native practitioners elsewhere within their department. Sports journalism therefore hopes that this relative position will enhance their professional claims. This study found that sports journalists were reinforcing the status quo rather than making a commitment to address the shortcomings inherent in the 'toy department' label. For instance, sports journalists in this study asserted the importance of developing contacts and attending press conferences in the professional sports environment. However, they did not show an awareness that the 'toy department' label is a criticism of the way that the occupational group approaches these practices in being too close to sources and lacking critical inquiry in their interviewing techniques.

This study, in focusing on sport as a specialist form of journalism, contributes towards a comprehensive understanding of the cultural politics within newsrooms and the nature of the professional struggle in the digital age. The findings highlight that the boundary work of sports journalism as a professional jurisdiction is internally contested within news organisations as well as externally contested with citizen journalists, bloggers, and sport public relations. Future research into sports journalism needs to recognise the two typologies of traditional and online journalists within sports desks and their stratified dimensions. Sports journalists situate their professional claims in traditional practice but this outlook will continue to be tested as digital audiences grow, print circulations decline, and newsroom resources are re-allocated.

\section{Funding}

The author(s) received no financial support for the research, authorship, and/or publication of this article. 


\section{Notes}

1. NUJ card is a reference to the National Union of Journalists, which is the trade union for journalists in the UK. The NUJ issues a membership press card that indicates professional journalist status.

2. 'The Kop' is a colloquial term to refer to a stand behind a goal at Liverpool's Anfield Stadium, consisting of home supporters considered to be particularly vociferous and intimidating.

3. 'Minute-by-minutes' is a reference to the chronological format within live blogs.

\section{References}

Abbott A (1988) The System of Professions: An Essay on the Division of Expert Labour. Chicago: University of Chicago Press.

Agarwal S and Barthel M (2015) The friendly barbarians: Professional norms and work routines of online journalists in the United States. Journalism 16(3): 276-291.

Aldridge M and Evetts J (2003) Rethinking the concept of professionalism: The case of journalism. British Journal of Sociology 54(4): 542-564.

Anderson CW (2008) Journalism: Expertise, authority, and power in democratic life. In: Hesmondhalgh D and Toynbee J (eds) The Media and Social Theory. Oxon: Routledge, pp. 248-264.

Anderson CW and Schudson M (2008) Objectivity, professionalism and truth seeking in journalism. In Wahl-Jorgensen K and Hanitzsch T (eds) The Handbook of Journalism Studies. London: Routledge, pp. 29-41.

Boyle R (2006) Sports Journalism: Context and Issues. London: Sage.

Boyle R and Haynes R (2009) Power Play: Sport, the Media and Popular Culture. Edinburgh: Edinburgh University Press.

Bradshaw P and Rohumaa L (2011) The Online Journalism Handbook. Harlow: Pearson Education.

Carlson M (2015) Introduction: The many boundaries of journalism. In Carlson M and Lewis S eds Boundaries of Journalism: Professionalism, Practices, and Participation. New York: Routledge, pp. 1-19.

Carlson M and Lewis S eds (2015) Boundaries of Journalism: Professionalism, Practices, and Participation. New York: Routledge.

Curran J (2011) Media and Democracy. Oxon: Routledge.

Deuze M (2004) What is multimedia journalism? Journalism Studies 5(2): 139-152.

Deuze M and Yeshua D (2001) Online journalists face new ethical dilemmas: Lessons from the Netherlands. Journal of Mass Media Ethics 16(4): 273-292.

Dowling D and Vogan T (2015) Can we snowfall this? Digital longform and the race for the tablet market. Digital Journalism 3(2): 209-224.

English P (2011) Online versus print: A comparative analysis of web-first sports coverage in Australia and the United Kingdom. Media International Australia 140(1): 147-156. 
Fahmy S (2008) How online journalists rank importance of news skills. Newspaper Research Journal 29(2): 23-39.

Fahy D and Nisbet M (2011). The science journalist online: Shifting roles and emerging practices. Journalism 12(7): 778-793.

Franks S and O’Neill D (2016) Women reporting sport: Still a man’s game? Journalism 17(4): 474-492.

Garrison B (1989) The evolution of professionalism in sports reporting. In: McPhail T and Jackson R (eds.) The Olympic Movement and the Mass Media. Calgary: Hurford Enterprises, pp. 57-68.

Greenslade R (2012) Journalistic lessons from Sandy Hook - how to find facts among the fiction. The Guardian online, 18 December. Available at: https://www.theguardian.com/media/greenslade/2012/dec/18/newtown-shooting-digitalmedia

Hartley J (2013) The online journalist between ideals and audiences: Towards a (more) audience-driven and source-detached journalism? Journalism Practice 7(5): 572-587.

Hutchins B and Boyle R (2017) A community of practice: Sport journalism, mobile media and institutional change. Digital Journalism 5(5): 496-512

Hutchins B and Rowe D (2012) Sport Beyond Television: The Internet, Digital Media and the Rise of Networked Sport. London: Routledge.

Karlsson M (2011) The immediacy of online news, the visibility of journalistic processes and a restructuring of journalistic authority. Journalism 12(3): 279-295.

Kronstad M and Eide M (2015) How online journalists learn within a non-formal context. Journal of Workplace Learning 27(3): 226-240.

Lange K, Nicholson M, and Hess R (2007) A new breed apart? Work practices of Australian Internet sport journalists. Sport in Society 10(4): 662-679.

Larson MS (1977) The Rise of Professionalism: A Sociological Analysis. Berkeley: University of California Press.

Lewis S (2012) The tension between professional control and open participation: Journalism and its boundaries. Information, Communication \& Society 15(6): 836-866.

McEnnis S (2013) Raising our game: Effects of citizen journalism on Twitter for professional identity and working practices of British sport journalists. International Journal of Sport Communication 6(4): 423-433.

McEnnis S (2016) Following the action: How live bloggers are reimagining the professional ideology of sport journalism. Journalism Practice 10(8): 967-982.

McEnnis S (2017) Playing on the same pitch: Attitudes of sports journalists towards fan bloggers. Digital Journalism 5(5): 549-566.

McEnnis S (2018) Sports journalism and cultural authority in the digital age. In: Burdsey D, Carter T and Doidge M (eds) Transforming Sport: Knowledges, Practices and Structures. Abingdon: Routledge. pp. 207-219.

Meltzer K and Martick E (2017) Journalists as communities of practice: Advancing a theoretical framework for understanding journalism. Journal of Communication Inquiry 41(3): 207226.

Morrison S (2014) The toy department shall lead us: Why sports media have always been newsroom innovators. Columbia Journalism Review. Available at https://archives.cjr.org/reports/the_toy_department_shall_lead.php 
Oates TP and Pauly J (2007). Sports journalism as moral and ethical discourse. Journal of Mass Media Ethics 22(4): 332-347.

Rowe D (2004) Sport, Culture and the Media. $2^{\text {nd }}$ edn. Buckingham: Open University Press.

Rowe D (2007) Sports journalism: Still the 'toy department' of the news media? Journalism 8(4): 385-405.

Rowe D (2017) Sports journalism and the FIFA scandal: Personalization, co-optation and investigation. Communication \& Sport 5(5): 515-533.

Salwen M and Garrison B (1998) Finding their place in journalism: Newspaper sports journalists' 'professional problems'. Journal of Sport \& Social Issues 22(1): 88-102.

Schudson M (2001) The objectivity norm in American journalism. Journalism 2(2): 149-170.

Singer J (2003) Who are these guys? The online challenge to the notion of journalistic professionalism. Journalism 4 (2): 139-163.

Singer J (2004). More than ink-stained wretches: The resocialization of print journalists in converged newsrooms. Journalism \& Mass Communication Quarterly, 81: 838-856

Singer J, Tharp MP and Haruta A (1999) Online staffers: Superstars or second-class citizens? Newspaper Research Journal 20(3): 29-47.

Smyth R and Murray S (2014) And Gazza Misses the Final. London: Constable.

Starkman D (2010) The hamster wheel. Columbia Journalism Review. Available at: https://archives.cjr.org/cover_story/the_hamster_wheel.php

Steen R (2014) Sports Journalism: A Multimedia Primer. 2nd edn. London: Routledge.

Strauss A and Corbin J (1990) Basics of Qualitative Research: Grounded Theory Procedures and Techniques. London: Sage.

Sugden J and Tomlinson A (2007) Stories from planet football and sportsworld: Source relations and collusion in sport journalism. Journalism Practice 1(1): 44-61.

Thurman N and Walters A (2013) Live blogging-digital journalism's pivotal platform? A case study of the production, consumption and form of live blogs at Guardian.co.uk. Digital Journalism 1(1): 82-101.

Waisbord S (2013) Reinventing Professionalism: Journalism and News in Global Perspective. Cambridge: Polity.

Whiteside E, Yu N, and Hardin, M (2012) The new "toy department”? A case study on differences in sports coverage between traditional and new media. Journal of Sports Media 7(1): 23-38.

Zelizer B (1992) Covering the Body: The Kennedy Assassination, the Media and the Shaping of Collective Memory. Chicago: University of Chicago Press.

Word count: 7,987 